\title{
Modeling and Fuzzy Command of a Wind Generator
}

\author{
Nejib Hamrouni, Amel Ghobber, Moncef Jraidi, Ahmed Dhouib \\ Department of Electric, Science Faculty of Tunis, University of Tunis El Manar, Tunis, Tunisia \\ Email address: \\ nejib.hamrouni@inrap.rnrt.tn (N. Hamrouni), hamrouni_nejib2003@yahoo.fr (N. Hamrouni)
}

\section{To cite this article:}

Nejib Hamrouni, Amel Ghobber, Moncef Jraidi, Ahmed Dhouib. Modeling and Fuzzy Command of a Wind Generator. Science Journal of Circuits, Systems and Signal Processing. Vol. 6, No. 4, 2017, pp. 35-43. doi: 10.11648/j.cssp.20170604.11

Received: November 14, 2017; Accepted: November 30, 2017; Published: January 2, 2018

\begin{abstract}
A problem of mechanical modeling and robustly stabilization of a wind generator is considered. To overcome the non-linearity of the system, the model of the wind generator is approximated by a Takagi-Sugeno fuzzy model. To stabilize the obtained fuzzy model, two command approaches were developed. They are the fuzzy controller using the parallel distributed compensation (PDC) and the $H_{\infty}$ controller based-fuzzy observer. Numerical optimization problems using linear matrix inequality (LMI) and convex techniques are used to analyze the stability of the wind generator. Finally, simulation examples illustrating the control performance and dynamic behavior of the wind generator under various command approaches are presented.
\end{abstract}

Keywords: Modeling, TS-Fuzzy Control, $\mathrm{H}_{\infty}$ Command, LMI Approach, Stability

\section{Introduction}

Wind energies were well developed and exploited and became competitive thanks to the evolution of the power electronics. Nevertheless, the optimal exploitation of the renewable energy sources encountered many problems which are related mainly to the uncertain variation of the wind speed. To resolve these problems and to improve the penetration rate and the stability level of the connected wind system, several controls are developed focusing this subject. These commands illustrate performance limits such as instability and implementation complexity.

Recently many studies have been devoted to the stability of the non-linear system. Fuzzy control constitutes a preferment command which has attracted an increasing attention because it can offer an effective solution to the control of complex, uncertain and undefined system [1-3]. The well-known Takagi-Sugeno (TS) fuzzy method has become a convenient approach for dealing with a complex system. This approach provides an effective representation of the system with the aid of fuzzy sets, fuzzy rules and a local linear model. The Takagi Sugeno fuzzy model [4] constitutes a productive way to describe and control the dynamics of nonlinear systems [5]. The TS fuzzy dynamics model is a system described by the fuzzy 'if-then' rules which offer local linear representation. The advantages of using this approach for design control are that the closed loop stability analysis using Lyapunov method becomes easier to apply and the controller synthesis can be reduced to convex problem [6]. Once the nonlinear models are transferred to a fuzzy model, control design can be carried out. Some of them are fuzzy controller using parallel distribution compensation (PDC) and the fuzzy observer-based $\mathrm{H}_{\infty}$ controller. The PDC approach employs multiple linear controllers corresponding to the locally linear plants [7]. Many applications illustrate the effectiveness of the TS models and parallel distribution compensation $[4,8]$. Fuzzy observer-based $\mathrm{H}_{\infty}$ controller has been developed in $[9,10]$. Stability and aptitude to reject exterior disturbances provided by this command approach were approved in [11].

In this work, the TS-fuzzy approach is used to approximate the nonlinear wind generator model. Two approaches of robust and powerful commands to stabilize the mechanical part of the wind generator are presented. In the first part, a fuzzy controller design uses the concept of PDC [7, 12] is studied. In the second part, a fuzzy observer-based $\mathrm{H}_{\infty}$ controller is developed in order to improve the performance of the system and to minimize the disturbance effect of the wind speed. Sufficient stability conditions are expressed in terms of LMI which can be solved very efficiently using convex optimization techniques [6]. Finally, simulation examples are given to illustrate both stability and robustness analysis of the proposed control systems. 


\section{Description and Modeling of the Wind Generator}

The drive train of the wind turbine generator system consists of the following elements: a blade-pitching mechanism, a hub with blades, a rotor shaft, a gearbox and generator. The common way to model the drive train is to treat the system as a number of discrete masses connected together by springs defined by damping and stiffness coefficients (Figure 1).

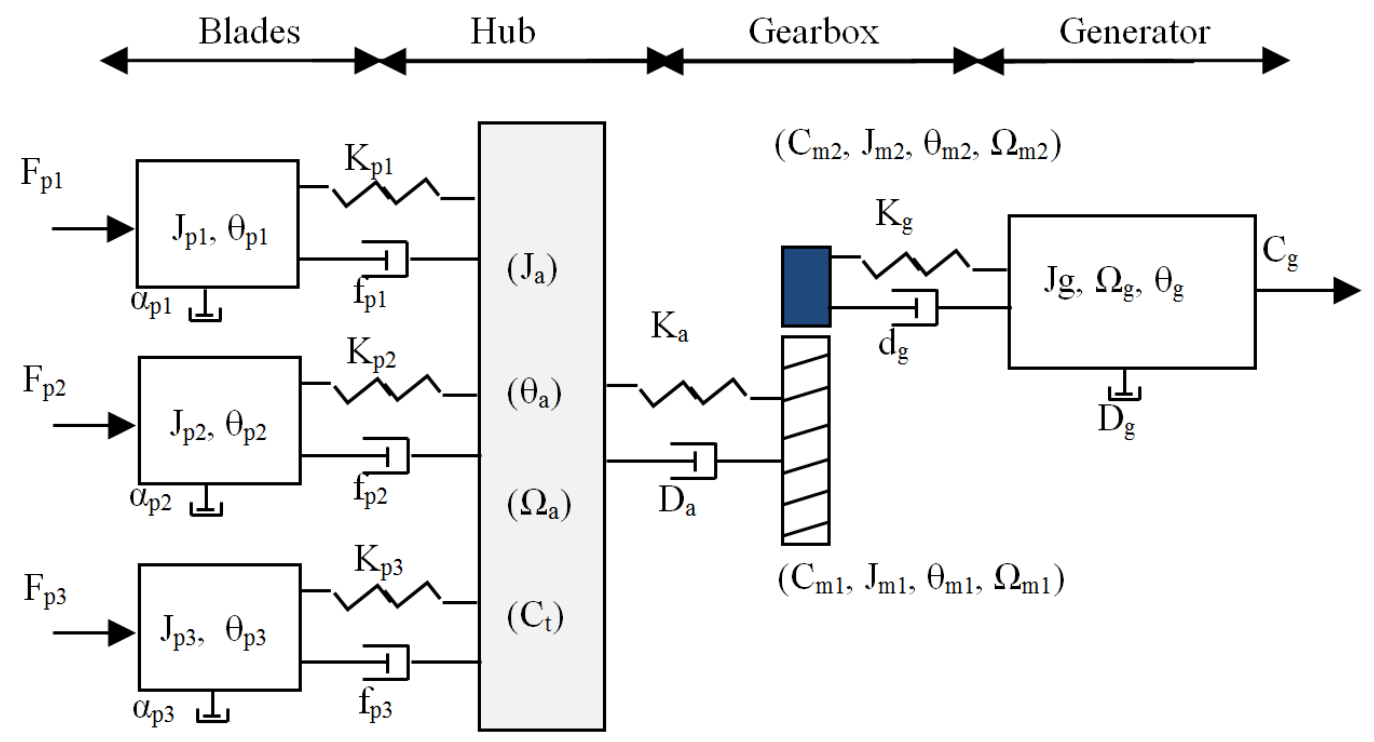

Figure 1. Transmission model of 6 masses connected together.

The aerodynamic part is made of three blades, hub, gearbox and generator. This system has six inertias; three blade inertias $\left(\mathrm{J}_{\mathrm{p} 1}, \mathrm{~J}_{\mathrm{p} 2}\right.$ and $\left.\mathrm{J}_{\mathrm{p} 3}\right)$, hub inertia $\mathrm{J}_{\mathrm{a}}$, gearbox inertia $\mathrm{J}_{\mathrm{m}}\left(\mathrm{J}_{\mathrm{m} 1}, \mathrm{~J}_{\mathrm{m} 2}\right)$ and generator inertia $J_{\mathrm{g}}$. The elasticity between adjacent masses is expressed by $\mathrm{K}_{\mathrm{p} 1}, \mathrm{~K}_{\mathrm{p} 2}, \mathrm{~K}_{\mathrm{p} 3}, \mathrm{~K}_{\mathrm{a}}$ and $\mathrm{K}_{\mathrm{g}}$. The mutual damping between adjacent masses is given by $f_{p 1}, f_{p 2}, f_{p 3}, D_{a}$ and $d_{g}$. There exist torque losses through external damping elements represented by $\alpha_{\mathrm{p} 1}, \alpha_{\mathrm{p} 2}$ and $\alpha_{\mathrm{p} 3} . \theta_{\mathrm{p} 1}, \theta_{\mathrm{p} 2}, \theta_{\mathrm{p} 3}, \theta_{\mathrm{a}}, \theta_{\mathrm{m}}$ and $\theta_{\mathrm{g}}$ represent respectively angular positions of the blades, the hub, the gearbox and the generator. $\Omega_{\mathrm{p} 1}, \Omega_{\mathrm{p} 2}, \Omega_{\mathrm{p} 3}, \Omega_{\mathrm{a}}, \Omega_{\mathrm{m}}\left(\Omega_{\mathrm{m} 1}\right.$, $\Omega_{\mathrm{m} 2}$ ) and $\Omega_{\mathrm{g}}$ are respectively the angular velocities of the blades, hub, gearbox and generator. $F_{p 1}, F_{p 2}$ and $F_{p 3}$ are aerodynamic torques acting on each blade. The sum of the blade torques constitutes the turbine torque $\mathrm{C}_{\mathrm{t}} \cdot \mathrm{C}_{\mathrm{m}}\left(\mathrm{C}_{\mathrm{m} 1}, \mathrm{C}_{\mathrm{m} 2}\right)$ and $\mathrm{C}_{\mathrm{g}}$ are respectively the gearbox and generator torques. It is assumed that the aerodynamic torque acting on the hub is zero.
In order to simplify the control of the wind generator, we introduce some simplifications on the six masse models. The turbine inertia can be calculated from the combined weight of the blades and the hub. Therefore, the mutual damping and elasticity between the hub and the three blades is ignored $\left(\mathrm{K}_{\mathrm{p} 1}=\mathrm{K}_{\mathrm{p} 2}=\mathrm{K}_{\mathrm{p} 3} \approx 0\right.$ and $\left.\mathrm{f}_{\mathrm{p} 1}=\mathrm{f}_{\mathrm{p} 2}=\mathrm{f}_{\mathrm{p} 3} \approx 0\right)$. The torque losses of the blades $\left(\alpha_{\mathrm{p} 1}, \alpha_{\mathrm{p} 2}\right.$ and $\left.\alpha_{\mathrm{p} 3}\right)$ are ignored because turbine speed is very weak. Moreover, it is assumed that the three blades have uniform weight distribution $\left(\mathrm{F}_{\mathrm{p} 1}=\mathrm{F}_{\mathrm{p} 2}=\mathrm{F}_{\mathrm{p} 3}=\mathrm{F}_{\mathrm{p}}\right)$ and the turbine torque is assumed to be equal to the sum of the torque acting on the various blades. Thus, the turbine can be looked as a large disk with small thickness and the wind system (three blades, hub, gearbox and generator) can be modeled by three masses coupled through a gearbox as indicated by Figure 2.

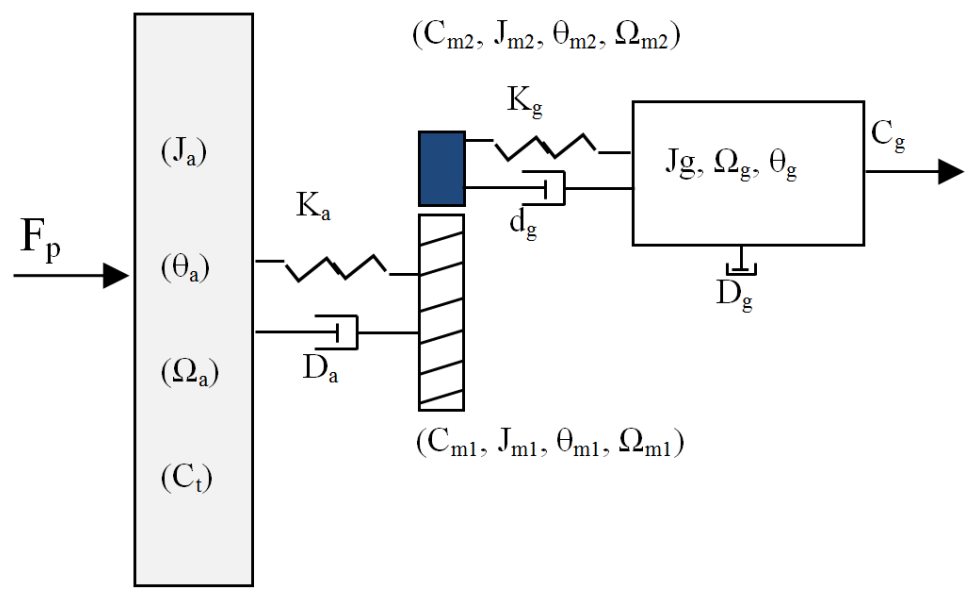

Figure 2. Three-mass model. 
In addition, compared with the mechanical characteristics of the blades and the generator, the gearbox inertia and mutual damping with adjacent masses moment of inertia are ignored. Therefore, the complex system can be simplified to be two-mass model through reforming the dynamic system with the equivalent stiffness and damping coefficients. As a consequence, the two-mass model contains two parts which represent the wind turbine and the generator. They are connected by a flexible shaft. This model will be used to investigate the control of the wind turbine.

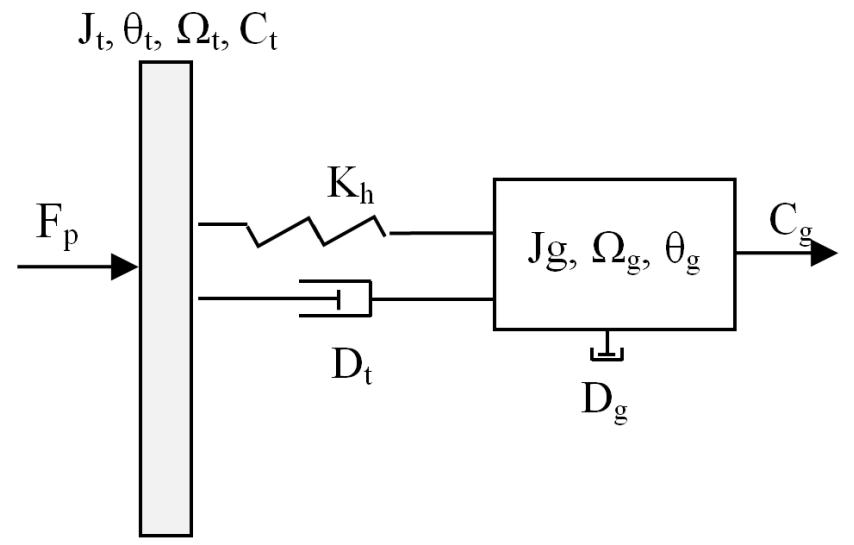

Figure 3. Two-mass model.

Referring to the simplified diagram given by Figure 3 and the Newton's second law for rotational masses, the dynamic system can be formulated with respect to the wind turbine rotor and the electromagnetic generator [13].

$$
\left\{\begin{array}{l}
j_{t} \ddot{\theta}_{t}+D_{t}\left(\Omega_{t}-\Omega_{g}\right)+K_{h}\left(\theta_{t}-\theta_{g}\right)=C_{a e r} \\
j_{g} \ddot{\theta}_{g}+D_{t}\left(\Omega_{g}-\Omega_{t}\right)+K_{h}\left(\theta_{g}-\theta_{t}\right)=-C_{g}
\end{array}\right.
$$

With

- $\mathrm{J}_{\mathrm{t}}, \mathrm{J}_{\mathrm{g}}$ : turbine and generator inertias $\left[\mathrm{kgm}^{2}\right]$.

- $\mathrm{C}_{\mathrm{aer}}, \mathrm{C}_{\mathrm{g}}$ : aerodynamic and electromagnetic torques of the turbine and generator $[\mathrm{Nm}]$.

- $\Omega_{\mathrm{t}}, \Omega_{\mathrm{g}}$ : angular speed of the turbine and generator $[\mathrm{rd} / \mathrm{s}]$. [rd].

$-\theta_{\mathrm{t}}, \theta_{\mathrm{g}}$ : angular displacement of the turbine and generator

- $\mathrm{K}_{\mathrm{h}}$ : elasticity between the turbine and the generator $[\mathrm{Nm} / \mathrm{rd}]$.

- $\mathrm{D}_{\mathrm{t}}$ : damping between the turbine and the generator $[\mathrm{Nms} / \mathrm{rd}]$.

According to eq. 1 , the model of the conversion system is written as:

$$
\left\{\begin{array}{l}
\frac{d\left(\Omega_{t}\right)}{d t}=\frac{K_{h}}{j_{t}} \theta_{s}-\frac{D_{t}}{j_{t}}\left(\Omega_{t}-\Omega_{g}\right)+\frac{C_{a e r}}{j_{t}} \\
\frac{d\left(\Omega_{g}\right)}{d t}=\frac{K_{h}}{j_{g}} \theta_{s}+\frac{D_{t}}{j_{g}}\left(\Omega_{t}-\Omega_{g}\right)-\frac{C_{g}}{j_{g}}
\end{array}\right.
$$

And $\theta_{\mathrm{s}}$ is the torsion angle of the blades. It is given by:

$$
\theta_{s}=\theta_{t}-\theta_{g}
$$

By differentiating equation (3) with respect to time and organizing equation (2) in term of $\Omega_{t}$ and $\Omega_{g}$, the overall model of the wind generator system can be given as follow:

$$
\left[\begin{array}{c}
\dot{\theta_{s}} \\
\dot{\Omega_{t}} \\
\dot{\Omega_{g}}
\end{array}\right]=\left[\begin{array}{ccc}
0 & 1 & -1 \\
-\frac{K_{h}}{J_{t}} & -\frac{D_{t}}{J_{t}} & \frac{D_{t}}{J_{t}} \\
\frac{K_{h}}{J_{g}} & \frac{D_{t}}{J_{g}} & -\frac{D_{t}}{J_{g}}
\end{array}\right]\left[\begin{array}{l}
\theta_{s} \\
\Omega_{t} \\
\Omega_{g}
\end{array}\right]+\left[\begin{array}{c}
0 \\
\frac{C_{a e r}(V, \beta)}{J_{t}} \\
-\frac{C_{g}(V, \beta)}{J_{g}}
\end{array}\right]
$$

With $x(t)=\left[\begin{array}{l}\theta_{s} \\ \Omega_{t} \\ \Omega_{g}\end{array}\right]$ is the vector of the variables of state and $z=\left[\begin{array}{l}V \\ \beta\end{array}\right]$ is the input vector and $\mathrm{C}_{\mathrm{g}}$ is the electromagnetic torque of the generator.

According to [14], the aerodynamic torque $C_{a e r}$ is a nonlinear function. It depends on the wind speed $\mathrm{V}$ and pitch angle $\beta$. It is given by:

$$
C_{a e r}(V, \beta)=\frac{0.5 * C_{\mathrm{p}}(\lambda, \beta) \rho \pi R^{2} V^{3}}{\Omega_{t}}
$$

With:

$$
\lambda=\frac{G \cdot V}{R \cdot \Omega_{g}}
$$

We assume that $z_{0}\left(V_{0}, \beta_{0}\right)$ is an equilibrium point. So we would like to find the linear system when $C_{a e r}(4)$ is close to $\mathrm{z}_{0}\left(\mathrm{~V}_{0}, \beta_{0}\right)$. Then the nonlinear system may be approximated by:

$$
C_{a e r}(V, \beta)=C_{a e r, \beta}\left(z_{0}\right) \beta+C_{a e r, V}\left(z_{0}\right) V
$$

In addition, the electromagnetic torque of the machine is a nonlinear function. It depends on the angular velocity $\Omega_{\mathrm{g}}$ and the operating speed $\Omega_{\mathrm{f}}$. It is approximated since [15], by:

$$
C_{g}=D_{g}\left(\Omega_{g}-\Omega_{f}\right)
$$

With $\mathrm{D}_{\mathrm{g}}$ is the damping between the generator and the nacelle $[\mathrm{Nms} / \mathrm{rd}]$.

It is better to use the mechanical representation instead of the electric representation. With this intention, we introduce the variable $\beta$ in order to obtain a command which was independent on the activation terms. It is supposed that the blade speed, around a value $\beta_{\mathrm{d}}$ placed in a linear area, can be written as [15]:

$$
\dot{\beta}=-\frac{1}{\tau_{\beta}} \beta+\frac{1}{\tau_{\beta}} \beta_{d}
$$

Where $\tau_{\beta}$ is the constant time of the blade movement.

Then, replacing $\mathrm{C}_{\mathrm{aer}}$ and $\mathrm{C}_{\mathrm{g}}$ by their expressions given by (8) and (9) in (4), we obtain the increased dynamic model of the wind generator. It can be expressed by [16]:

$$
\left\{\begin{array}{c}
\dot{x}(t)=A(z) x(t)+B_{1} u(t)+B_{2} V \\
y(t)=C x(t)
\end{array}\right.
$$

With: 


$$
\begin{gathered}
\mathrm{A}(\mathrm{z})=\left[\begin{array}{cccc}
0 & 1 & -1 & 0 \\
-\frac{\mathrm{K}_{\mathrm{h}}}{\mathrm{J}_{\mathrm{t}}} & -\frac{\mathrm{D}_{\mathrm{t}}}{\mathrm{t}} & \frac{\mathrm{D}_{\mathrm{t}}}{\mathrm{J}_{\mathrm{t}}} & \frac{\mathrm{Caer}_{\beta}\left(\mathrm{z}_{0}\right)}{\mathrm{Jt}} \\
\frac{\mathrm{Kh}_{\mathrm{h}}}{\mathrm{Jg}} & \frac{\mathrm{D}_{\mathrm{t}}}{\mathrm{Jg}} & -\frac{\left(\mathrm{D}_{\mathrm{t}}+\mathrm{D}_{\mathrm{g}}\right)}{\mathrm{Jg}} & 0 \\
0 & 0 & 0 & -\frac{1}{\tau_{\beta}}
\end{array}\right] ; \mathrm{B}_{1}=\left[\begin{array}{cc}
0 & 0 \\
0 & 0 \\
0 & \frac{\mathrm{Dg}_{\mathrm{g}}}{\mathrm{Jg}_{\mathrm{g}}} \\
\frac{1}{\tau_{\beta}} & 0
\end{array}\right] ; B_{2}=\left[\begin{array}{c}
0 \\
\frac{C_{a e r}\left(z_{0}\right)}{J_{t}} \\
0 \\
0
\end{array}\right] ; x(t)=\left[\begin{array}{c}
\theta_{s} \\
\Omega_{t} \\
\Omega_{g} \\
\beta
\end{array}\right] \quad u=\left[\begin{array}{c}
\beta_{d} \\
\Omega_{f}
\end{array}\right] \\
y=\Omega_{g} \text { and } C=\left[\begin{array}{cccc}
0 & 0 & 1 & 0
\end{array}\right] ; z=\left[\begin{array}{l}
V \\
\beta
\end{array}\right]
\end{gathered}
$$

\subsection{TS Fuzzy Model}

The objective of this approach is to approximate the nonlinear system by linearized sub-systems. It has been used as an alternative to classical models to capture dynamic performances under different operating conditions and in different functioning zones.

The description of the nonlinear system in terms of "If-Then" rules combined with a mathematical description of non-linear systems is called a Takagi-Sugeno fuzzy model. The concept of sector nonlinearity provided means for exact approximation of nonlinear systems by fuzzy blending of set locally linearized sub-systems. The TS system is defined as follows:

If $z_{1}(t)$ is $F_{i 1}$ and $\ldots$ and $z_{p}(t)$ is $F_{i p}$ then [17]:

$$
\dot{x}(t)=\frac{\sum_{i=1}^{M} w_{i}(z(t))\left(A_{i} x(t)+B_{i} u(t)\right)}{\sum_{i=1}^{M} w_{i}(z(t))}=\sum_{i=1}^{M} \mu_{i}(z(t))\left(A_{i} x(t)+B_{i} u(t)\right)
$$

Where:

$$
\mu_{i}(z(t))=\frac{w_{i}(z(t))}{\sum_{i=1}^{M} w_{i}(z(t))^{\prime}}, w_{i}(z(t))=\prod_{j=1}^{p} F_{i j}\left(z_{j}(t)\right) \text { and } w_{i}(z(t)) \geq 0 \text { When } \mathrm{t} \geq 0 .
$$

The output signal is obtained by the same technique:

$$
y(t)=\sum_{i=1}^{M} \mu_{i}(z(t)) C_{i} x(t)
$$

The term $\mu_{i}(z(t))$ determines the activation terms of the associated local models. According to the functioning zone of the system, these terms indicate the contribution of the local model. They allow a progressive passage of a local model to another and they depend on the state vector. They can be in triangular or Gaussian forms. They satisfy the conditions given in [17].

$$
\left\{\begin{aligned}
\sum_{i=1}^{M} \mu_{i}(x(t)) & =1 \\
0<\mu_{i}(x(t)) & \leq 1
\end{aligned}\right.
$$

\subsection{TS Fuzzy Description of the Wind Generator}

We consider the TS fuzzy models based on the nonlinear sectors $[18,19]$ to represent the nonlinear model of the wind system composed of a turbine, a driving shaft and an induction machine. This approach based on the transformation of the scalar functions and the bornitude of the continuous variables $V$ and $\beta$. These variables are limited as given by the following equations.

$$
V_{\min } \leq V \leq V_{\max } \text { and } \beta_{\min } \leq \beta \leq \beta_{\max }
$$

According to the model given by the equation (10), the system has two non linearties depending on $\mathrm{V}$ and $\beta$. To linearize this model, we will use the presentation of TS previously presented. For those non-linearities, the base comprises four rules 'If-Then'. Thus, the nonlinear wind system is represented by the following fuzzy model:

$$
\begin{aligned}
& \text { If } \beta \text { is } F_{1}{ }^{1} \text { and } V \text { is } F_{2}{ }^{1} \text { then }\left\{\begin{array}{c}
\dot{x}(t)=A_{1} x(t)+B_{1} u(t)+B_{21} w \\
y=C_{1} x(t)
\end{array}\right. \\
& \text { If } \beta \text { is } F_{1}{ }^{1} \text { and } V \text { is } F_{2}{ }^{2} \text { then }\left\{\begin{array}{c}
\dot{x}(t)=A_{2} x(t)+B_{1} u(t)+B_{22} w \\
y=C_{2} x(t)
\end{array}\right. \\
& \text { If } \beta \text { is }{F_{1}}^{2} \text { and } V \text { is } F_{2}{ }^{1} \text { then }\left\{\begin{array}{c}
\dot{x}(t)=A_{3} x(t)+B_{1} u(t)+B_{23} w \\
y=C_{3} x(t)
\end{array}\right.
\end{aligned}
$$




$$
\text { If } \beta \text { is } F_{1}{ }^{2} \text { and } V \text { is } F_{2}{ }^{2} \text { then }\left\{\begin{array}{c}
\dot{x}(t)=A_{4} x(t)+B_{1} u(t)+B_{24} w \\
y=C_{4} x(t)
\end{array}\right.
$$

Then the inferred system is given by:

$$
\left\{\begin{array}{c}
\dot{x}(t)=\sum_{i=1}^{4} \mu_{i}(z(t))\left(\left(A_{i} x(t)+B_{1} u(t)+B_{2 i} w\right)\right) \\
y=\sum_{i=1}^{4} \mu_{i}\left(z(t) C_{i} x(t)\right.
\end{array}\right.
$$

Where $\mu_{\mathrm{i}}(\mathrm{z}(\mathrm{t}))$ are activation terms of the subsystems. They are given by:

$$
\left\{\begin{array}{l}
\mu_{1}(\mathrm{z})=\mathrm{F}_{1}{ }^{1}(\beta) \mathrm{F}_{2}{ }^{1}(\mathrm{~V}) \\
\mu_{2}(\mathrm{z})=\mathrm{F}_{1}{ }^{1}(\beta) \mathrm{F}_{2}{ }^{2}(\mathrm{~V}) \\
\mu_{3}(\mathrm{z})=\mathrm{F}_{1}{ }^{2}(\beta) \mathrm{F}_{2}{ }^{1}(\mathrm{~V}) \\
\mu_{4}(\mathrm{z})=\mathrm{F}_{1}{ }^{2}(\beta) \mathrm{F}_{2}{ }^{2}(\mathrm{~V})
\end{array}\right.
$$

$$
\begin{gathered}
A_{1}=A_{2}=\left[\begin{array}{cccc}
0 & 1 & -1 & 0 \\
-\frac{K_{h}}{J_{t}} & -\frac{D_{t}}{J_{t}} & \frac{D_{t}}{J_{t}} & \frac{C_{a e r, \beta 1}}{J_{t}} \\
\frac{K_{h}}{J_{g}} & \frac{D_{t}}{J_{g}} & -\frac{\left(D_{t}+D_{g}\right)}{J_{g}} & 0 \\
0 & 0 & 0 & -\frac{1}{\tau_{\beta}}
\end{array}\right] ; A_{3}=A_{4}=\left[\begin{array}{cccc}
0 & 1 & -1 & 0 \\
-\frac{K_{h}}{J_{t}} & -\frac{D_{t}}{J_{t}} & \frac{D_{t}}{J_{t}} & \frac{C_{a e r, \beta 2}}{J_{t}} \\
\frac{K_{h}}{J_{g}} & \frac{D_{t}}{J_{g}} & -\frac{\left(D_{t}+D_{g}\right)}{J_{g}} & 0 \\
0 & 0 & 0 & -\frac{1}{\tau_{\beta}}
\end{array}\right] \\
B_{21}=B_{23}=\left[\begin{array}{c}
0 \\
\frac{C_{a e r, V 1}}{J_{t}} \\
0 \\
0
\end{array}\right] ; B_{1}=\left[\begin{array}{cc}
0 & 0 \\
0 & 0 \\
0 & \frac{D_{g}}{J_{g}} \\
\frac{1}{\tau_{\beta}} & 0
\end{array}\right] ; B_{22}=B_{24}=\left[\begin{array}{c}
0 \\
\frac{C_{a e r, V 2}}{J_{t}} \\
0 \\
0
\end{array}\right] ; C=\left[\begin{array}{llll}
0 & 0 & 1 & 0
\end{array}\right]
\end{gathered}
$$

With:

$$
\begin{aligned}
& C_{a e r, \beta 1}=C_{a e r, \beta}\left(\beta=\beta_{1}\right), C_{a e r, \beta 2}=C_{a e r, \beta}\left(\beta=\beta_{2}\right) \\
& C_{a e r, V 2}=C_{a e r, V}\left(V=V_{2}\right), C_{a e r, V 1}=C_{a e r, V}\left(V=V_{1}\right)
\end{aligned}
$$

\section{Stabilisation of the Wind Generator}

\subsection{By Fuzzy Controller: Parallel Distribution Compensation}

The concept of this command, named parallel distributed compensation (PDC), is used to stabilize the fuzzy system. It employs linear controllers corresponding to the locally linear plant model. The general diagram of the PDC is given by Figure 4.

The general structure of the PDC is given by [20]: If $z_{1}(t)$ is $\mathrm{M}_{1}$ and $\mathrm{z}_{2}(\mathrm{t})$ is $\mathrm{M}_{2} \ldots$, and $\mathrm{z}_{\mathrm{p}}$ is $\mathrm{M}_{\mathrm{p}}$ then $u(t)=-K_{j} x(t)$, $\mathrm{j}=1,2 \ldots \mathrm{M}$. Consequently the overall PDC fuzzy controller is represented by:
With $F_{i}^{j}$ are the degrees of membership function of the activation terms. They are given by:

$$
\left\{\begin{array}{l}
F_{1}{ }^{1}(\beta)=\frac{\beta-\beta_{1}}{\beta_{2}-\beta_{1}} \\
F_{1}{ }^{2}(\beta)=\frac{\beta_{2}-\beta}{\beta_{2}-\beta_{1}} \\
F_{2}{ }^{1}(V)=\frac{V-V_{1}}{V_{2}-V_{1}} \\
F_{2}{ }^{2}(V)=\frac{V_{2}-V}{V_{2}-V_{1}}
\end{array}\right.
$$

With $\mathrm{V}_{1}=\mathrm{V}_{\min }, \mathrm{V}_{2}=\mathrm{V}_{\max }, \beta_{1}=\beta_{\min }$ and $\beta_{2}=\beta_{\max }$.

For $\mathrm{i}=\{1 \ldots 4\}$, the matrices $A_{i} B_{1}, B_{2 i}$ and $\mathrm{C}$ are given by: 


$$
\left\{\begin{array}{c}
-X A_{i}^{T}-A_{i} X+B_{i} M_{i}+\left(B_{i} M_{j}\right)^{T}>0 \\
-X A_{i}^{T}-A_{i} X-X A_{j}^{T}-A_{j} X+M_{j}^{T} B_{i}^{T}+B_{i} M_{j}+M_{i}^{T} B_{j}^{T}+B_{j} M_{i} \geq 0
\end{array}\right.
$$

The objective of the command is in finding $\mathrm{K}_{1}, \mathrm{~K}_{2}, \mathrm{~K}_{3}$ and $\mathrm{K}_{4}$ and $\mathrm{P}>0$ that satisfy the conditions presented by equation 20 . An approach to design a stable fuzzy controller for the wind generator is to transform the condition in equation 20 into convex problem [1, 21-23]. The solution of the stable PDC controller design problem via linear matrix inequalities (LMI) for the system leads to:

$$
K_{j}=M_{j} X^{-1} \text { with } P=X^{-1}
$$

If the solution of the LMI (eq. 20) is found, it means that local state feedback gains $K_{j}(\mathrm{j}=1,2,3$ and 4) provide quadratic stability of the closed loop TS fuzzy systems. Hence, using matlab toolbox, the controller parameters are found to be:

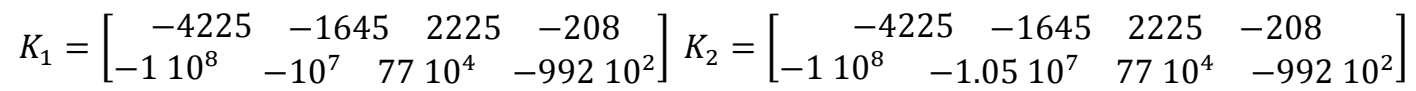

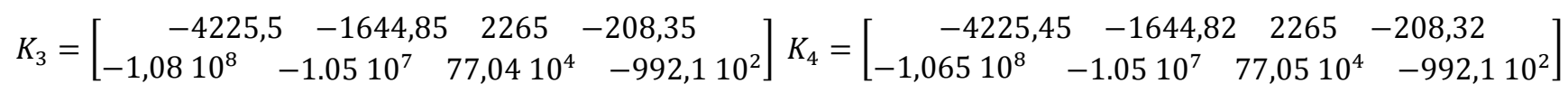

Table 1. Parameters of the wind system.

\begin{tabular}{lll}
\hline Symbol & Quantity & Value \\
\hline $\mathrm{K}_{\mathrm{h}}$ & Elasticity of driving shaft & $1.566 \times 106 \mathrm{Nm}^{-1}$ \\
$\mathrm{D}_{\mathrm{r}}$ & Damping factor shaft-nacelle & $3029.5 \mathrm{Nmsrad}^{-1}$ \\
$\mathrm{D}_{\mathrm{g}}$ & Damping factor IG-gearbox & $15.993 \mathrm{Nmsrad}^{-1}$ \\
$\mathrm{~J}_{\mathrm{g}}$ & Inertia of IG & $5.9 \mathrm{kgm}^{2}$ \\
$\mathrm{~J}_{\mathrm{p}}$ & Inertia of blades & $830000 \mathrm{kgm}^{2}$ \\
$\rho$ & Air density & $1.225 \mathrm{kgm}^{-3}$ \\
$\mathrm{R}$ & Blade radius & $30.3 \mathrm{~m}$ \\
$\tau \beta$ & Time constant of the blade movement & $100 \mathrm{~ms}$ \\
$\mathrm{P}$ & Rated power of the IG & $1 \mathrm{MW}$ \\
$\mathrm{p}$ & Pole pair number of the IG & 3 \\
$\lambda_{\text {opt }}$ & Optimal specific speed & 7 \\
$\mathrm{C}_{\mathrm{pmax}}$ & Coefficient of maximal power & 0.48 \\
$\gamma$ & Desired level disturbance attenuation & 0.6 \\
$\mathrm{C}_{\text {aer, } \beta 1}$ & Aerodynamic torque corresponding to the pitch angle $\beta 1$ & $723980 \mathrm{Nm}$ \\
$\mathrm{C}_{\text {aer, }, \beta 2}$ & Aerodynamic torque corresponding to the pitch angle $\beta 2$ & $376070 \mathrm{Nm}$ \\
$\mathrm{C}_{\text {aer, }, 1}$ & Aerodynamic torque corresponding to the wind speed V1 & $106440 \mathrm{Nm}$ \\
$\mathrm{C}_{\text {aer, }, 22}$ & Aerodynamic torque corresponding to the wind speed V2 & $85370 \mathrm{Nm}$ \\
\hline
\end{tabular}

The choice of the wind speed profile is arbitrary. For that, we consider a sinusoidal form of a wind speed which varies between 17 and $32 \mathrm{~km} / \mathrm{h}$. The main objective is to test and analyze the performance of the PDC controller.

(a)

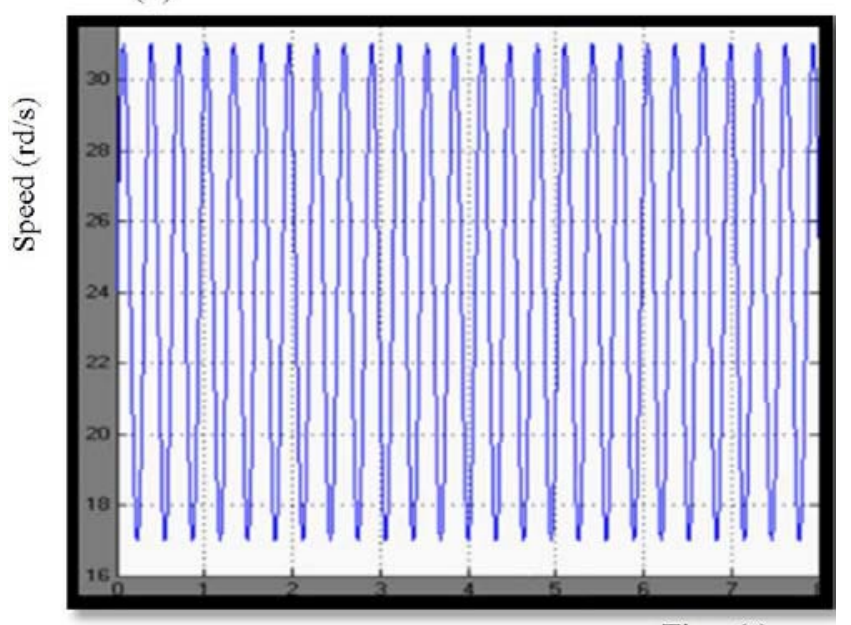

Time (s) (b)

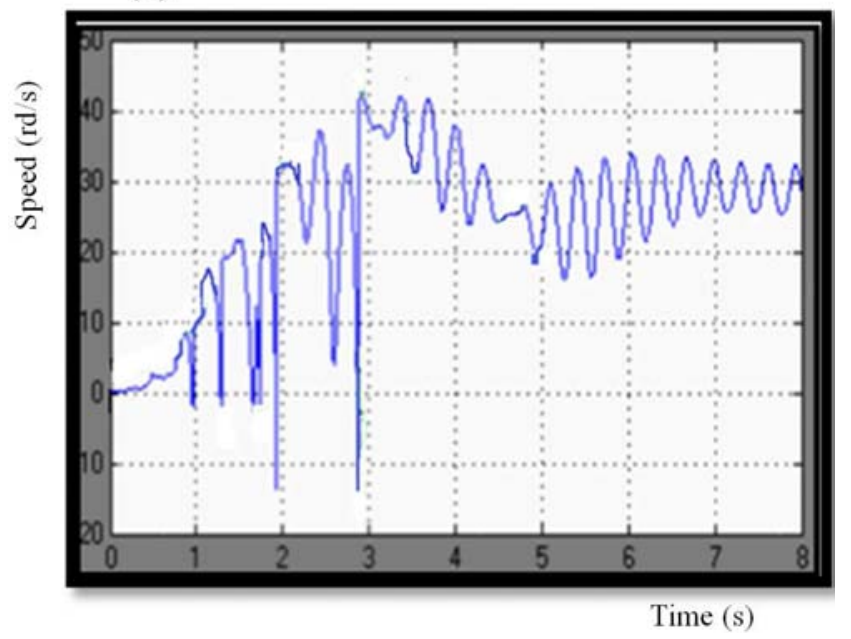

Figure 5. Wind profile and speed variation of the $I G$.

We notice that the form of the wind speed generates disturbances on the machine speed according to Figure 5a. The generator speed is not stable and oscillates (Figure 5b). These oscillations can cause vibrations and harmful effects 
on the driving shaft. The PDC controller is insufficient and does not allow a stability of the overall system. To overcome this problem, we will use another preferment command which is able to eliminate the oscillatory effect on the operating of the overall system.

\subsection{By Fuzzy Observer-Based $H_{\infty}$ Controller}

The approach is to develop a robust command which permits to obtain robustness stability in analytical way.
According to the TS system represented by equation12, some state variables are un-measurable. Hence, it was obligatory to synthesize an observer which make possible to estimate those variables $\left(\theta_{\mathrm{s}}\right.$ and $\left.\beta\right)$. The design of fuzzy observer obliges that the local models of the system should be locally observables, and is obtained by interpolation of several Luenberger observer. The observer is introduced as follows:

If $\hat{z}_{1}(t)$ is $\mathrm{F}_{\mathrm{i} 1}$ and... $\hat{z}_{\mathrm{p}}(t)$ is $\mathrm{F}_{\mathrm{ip}}$, then for $\mathrm{i}=1 \ldots 4$, the observer states are governed by [24]:

$$
\left\{\begin{array}{c}
\dot{\hat{x}}(t)=A_{i} \hat{x}(t)+B_{1} u(t)+B_{2 i} w(t)-L_{i}(y(t)-\hat{y}(t)) \\
\hat{y}(t)=C_{i} \hat{x}(t)
\end{array}\right.
$$

Where $L_{i}$ is the observer gain for the $i^{\text {th }}$ observer rule. The overall fuzzy observer is represented as follows:

$$
\left\{\begin{array}{c}
\dot{\hat{x}}(t)=\sum_{i=1}^{4} \mu_{i}(\hat{z}(t))\left(A_{i} \hat{x}(t)+B_{1} u(t)+B_{2 i} w(t)-L_{i}(y(t)-\hat{y}(t))\right) \\
\hat{y}(t)=\sum_{i=1}^{4} \mu_{i}(\hat{z}(t)) C_{i} \hat{x}(t)
\end{array}\right.
$$

Where $\hat{x}(t) \epsilon \mathfrak{R}^{n}$ and $\hat{y}(t) \in \mathfrak{R}^{h}$ are respectively the estimated state and output vector.

The stabilization of the generator speed is essentially a disturbance rejection problem. Thus, a robust control using $\mathrm{H}_{\infty}$ technique is well adopted to resolve this kind of control problem. It is assumed that the fuzzy systems are locally controllable. Hence, a fuzzy controller with the following rules can be used.

If $\hat{z}_{1}(t)$ is $\mathrm{F}_{\mathrm{i} 1}$ and... $\hat{z}_{\mathrm{p}}(t)$ is $\mathrm{F}_{\mathrm{jp}}$

Then $u(t)=K_{j} \hat{x}(t)$, for $\mathrm{j}=1$ to 4 .

Hence, the fuzzy control is given by [9]:

$$
u(t)=\sum_{j=1}^{4} \mu_{j}(\hat{z}(t)) K_{j} \hat{x}(t)
$$

With $K_{j}$ are the controller gains.

Let use a new variable which present the estimation error. It is given by:

$$
e(t)=\hat{x}(t)-x(t)
$$

The closed loop fuzzy model of the wind system integrating the TS model (15), the fuzzy observer (23) and the controller (24) became:

$$
\left(\begin{array}{c}
\dot{\bar{x}}(\mathrm{t}) \\
\mathrm{z}(\mathrm{t})
\end{array}\right)=\sum_{\mathrm{i}=1}^{4} \sum_{\mathrm{j}=1}^{4} \mu_{\mathrm{j}}(\mathrm{z}(\mathrm{t})) \mu_{\mathrm{i}}(\mathrm{z}(\mathrm{t}))\left(\begin{array}{cc}
\overline{\mathrm{A}}_{\mathrm{ij}} & \overline{\mathrm{B}}_{\mathrm{i}} \\
\overline{\mathrm{C}} & 0
\end{array}\right)\left(\begin{array}{c}
\overline{\mathrm{x}}(\mathrm{t}) \\
\mathrm{w}(\mathrm{t})
\end{array}\right)
$$

With:

$$
\bar{A}_{i j}=\left(\begin{array}{cc}
A_{i}+B_{1} K_{j} & B_{1} K_{j} \\
0 & A_{i}+L_{i} C
\end{array}\right) ; \bar{B}_{i}=\left(\begin{array}{c}
B_{2 i} \\
0
\end{array}\right) ; \bar{C}=\left(\begin{array}{ll}
C & 0
\end{array}\right)
$$

The general diagram of the fuzzy observer-based $\mathrm{H}_{\infty}$ controller is given by Figure 6 .

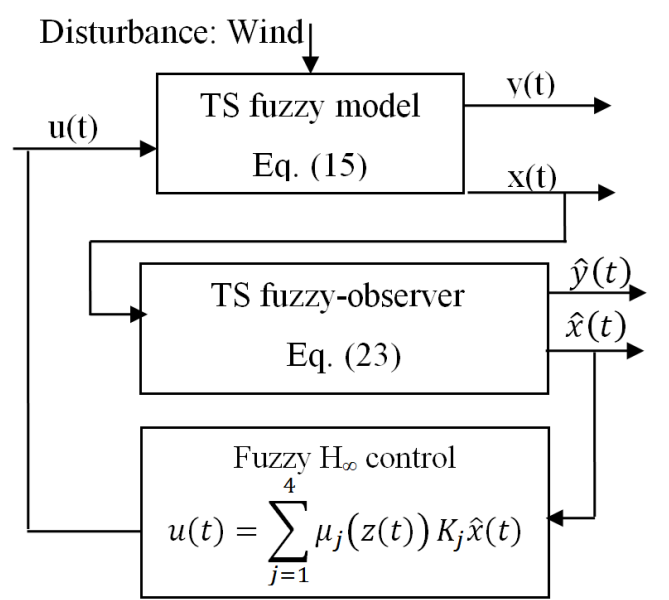

Figure 6. General diagram of the $H_{\infty}$ command with fuzzy observer.

For the formulation of the main result, we recall the following theorem and definition.

Definition: given a scalar $\gamma>0$, system (26) is stable with $\mathrm{H}_{\infty}$ disturbance attenuation $\gamma$ if it is exponentially stable with:

$$
\int_{0}^{\infty} z^{T}(t) z(t)-\gamma^{2} w^{T}(t) d(t)<0
$$

$\gamma$ is the desired level disturbance attenuation [6].

Theorem: the system (26) is stable with $\mathrm{H}_{\infty}$ disturbance attenuation $\gamma$, if there are symmetrical matrices $X>0, Y>0$, $Q_{i}>0, P_{i}, M_{i}$ and $J_{i}$ which satisfy the following linear matrix inequalities for $\mathrm{i}<\mathrm{j}=\{1.2,3.4\}[6]$ :

$$
X A_{i}{ }^{T}+A_{i} X+B_{1} M_{i}+M_{1}{ }^{T} B_{1}{ }^{T}+\gamma^{-2} B_{2 i} B_{2 i}{ }^{T}<P_{i}
$$


With the controller and observer gains are given by:

$$
\left\{\begin{array}{c}
K_{i}=M_{i} X^{T} \\
L_{i}=Y^{T} J_{i}
\end{array}\right.
$$

By applying the above theorem and the LMI optimization toolbox in matlab, to solve the equations 29-32, with four fuzzy rules, we obtain set feasible solutions. Hence, the controller parameters are:

$$
\begin{gathered}
K_{1}=10^{6}\left[\begin{array}{cccc}
0.0273 & 0.0000 & -0.0001 & -0.0000 \\
2.1542 & 0.0042 & -0.0042 & 0.0000
\end{array}\right] K_{2}=10^{6}\left[\begin{array}{cccc}
0.0275 & 0.0000 & -00001 & 0.0000 \\
2.1543 & 0.0042 & -0.0042 & 0.0000
\end{array}\right] \\
K_{3}=10^{6}\left[\begin{array}{cccc}
0.1096 & 0.0002 & -0.0002 & 0 \\
2.1504 & 0.0042 & -0.0042 & 0
\end{array}\right] K_{4}=10^{6}\left[\begin{array}{cccc}
0.1022 & 0.0002 & -0.0002 & 0 \\
2.15043 & 0.0042 & -0.0042 & 0
\end{array}\right]
\end{gathered}
$$

The observer gains are given by:

$$
L_{1}=\left[\begin{array}{c}
-0.6766 \\
-1.367 \\
-0.6541610^{3} \\
0.5244
\end{array}\right] ; L_{2}=\left[\begin{array}{c}
-0.5749 \\
-1.1588 \\
-0.548810^{3} \\
0.3478
\end{array}\right] ; L_{3}=\left[\begin{array}{c}
-0.5442 \\
-1.1062 \\
-0.5210^{3} \\
0.475
\end{array}\right] ; L_{4}=\left[\begin{array}{c}
-0.6043 \\
-1.2213 \\
-0.5727410^{3} \\
0.3947
\end{array}\right]
$$

Figure 7 represents the variation curve of the generator speed. A stabilization of the generator speed around $30 \mathrm{rd} / \mathrm{s}$ is ensured. The proposed control minimizes the generator speed ripple and maintains stability of the system during wind disturbances. Thus, this result demonstrates the performances of the command which is insensitive to the disturbance coming from the variation of the wind speed. The command seems a powerful technique for the disturbance rejection. In addition, the generator speed follows its reference with an error equal to $8 \%$.

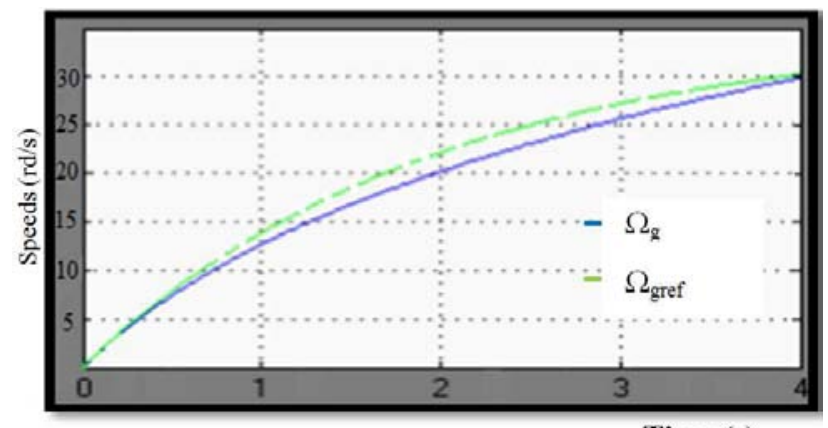

Time (s)

Figure 7. Variation curve of the generator speed (measure and reference).

(a)

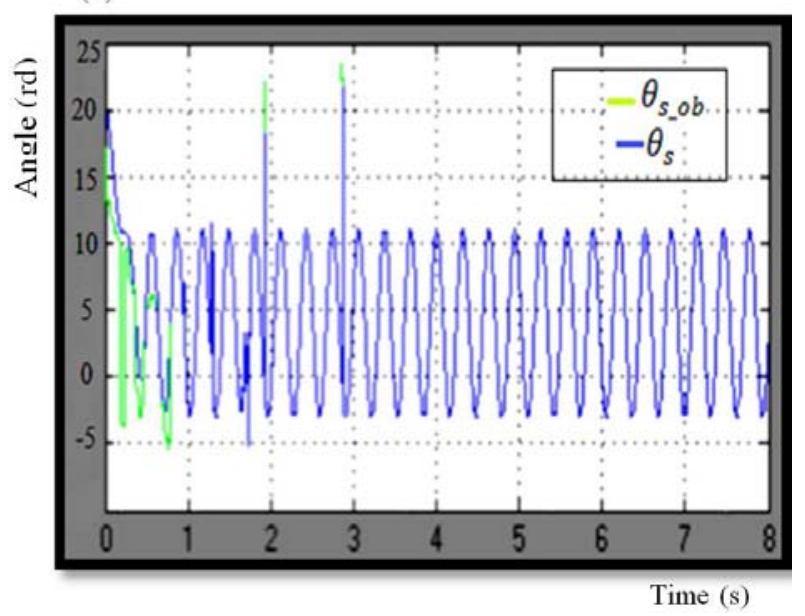

(b)

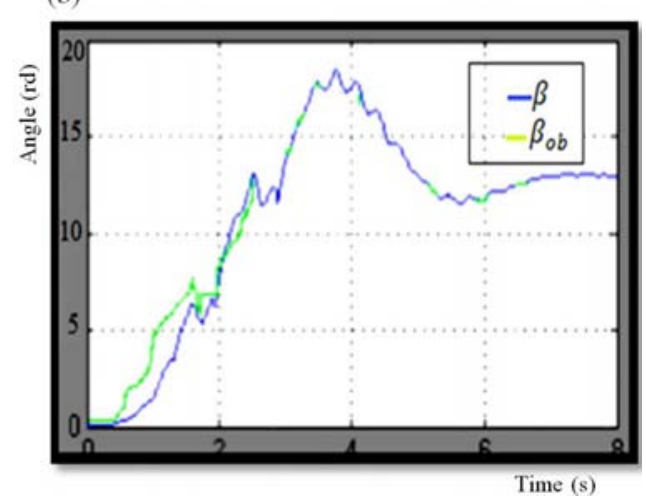

Figure 8. Variation of the state variables of the system: (a): torsion angle; (b): pitch angle.

Curve 8 represents the variation of the state variables of the TS fuzzy system. Figure 8 a represents the estimated and measure angle torsion of the driving shaft. Figure $8 \mathrm{~b}$ represents the variation of the pitch angle of the blades. The measured and estimated values are confused justifying consequently the performances of fuzzy observer-based $\mathrm{H}_{\infty}$ controller.

\section{Conclusion}

In this paper, an approach of modeling and control of a nonlinear system based-wind generator is discussed. In the first part, a TS fuzzy model is used to approximate the dynamics of wind generator composed of a turbine, a driving shaft and an induction machine. In the second part, two command approaches are developed around the complex system in order to stabilize the mechanical model and to minimize the generator speed ripple. Numerical optimization problems using linear matrix inequality and convex techniques are used to design the controller and the observer parameters.

Stability results for closed model based fuzzy controller using the concept of PDC have been examined assuming that all of the system states are measurable. The generator speed 
curve shows that the fuzzy controller can't stabilize the response of system when the wind speed varies. The proposed command scheme using fuzzy observer-based $\mathrm{H}_{\infty}$ controller illustrates some good performances. It minimizes the generator speed ripple, maintains stability of the system during wind disturbances and permits the attenuation of the external disturbances. The obtained results illustrate the effectiveness of this approach to stabilize the nonlinear system. Moreover, they showed the ability of the command to reject the disturbances and make possible to obtain a stable wind generator without oscillations. Therefore, we consider that the fuzzy observer-based $\mathrm{H}_{\infty}$ controller is appropriate for the nonlinear system control with external disturbances.

\section{References}

[1] S. G. Cao, N. W. Rees, G. Feng, Analysis and design for a class of complex control systems part II: fuzzy controller design, Automatica, 33 (1997) 1029-1039.

[2] G. Feng, A survey on analysis and design of model-based fuzzy control systems, IEEE Transactions on Fuzzy Systems, 14 (2006) 676-697.

[3] G. Feng, Analysis and Synthesis of Fuzzy Control Systems: A Model-Based Approach, in: CRC Press, New York, 2010.

[4] T. Takagi, M. Sugeno, Fuzzy identification of systems and its applications to modeling and control, IEEE Trans. Syst, 15 (1985) 116- 132.

[5] S. G. Cao, N. W. Rees, G. Feng, Ho control of uncertain fuzzy continuous time systems, IEEE Transactions on Fuzzy Systems, 8 (2000) 171-190.

[6] J. Park, J. Kim, D. Park, LMI-based design of stabilizing fuzzy controllers for nonlinear systems described by TakagiSugeno fuzzy model, Fuzzy Sets Syst., 122 (2001) 73-82.

[7] S. K. Hong, R. Langari, An LMI-based fuzzy control system design with TS framework, Infor. Sci., 123 (2000) 163-179.

[8] K. R. Lee, E. T. Jeung, H. B Park, Robust fuzzy Hœ control for uncertain nonlinear systems via state feedback: an LMI approach, International Journal of Fuzzy Sets and Systems, 120 (2001)123-134.

[9] K. Tanaka, H. O. Wang, Fuzzy control systems design and analysis: a linear matrix inequality approach, Wiley, New York, 2001.

[10] K. Tanaka, H. O Wang, Fuzzy regulators and fuzzy observers: a linear matrix inequality approach, Proc. 36th IEEE Conf. on Decision and Control, 6 (1997) 1315-1320.
[11] K. Tanaka, T. Ikeda, H. O. Wang, Fuzzy regulators and fuzzy observers, IEEE Trans. Fuzzy Syst., 6 (1998) 250- 256.

[12] E. Kamal, M. Koutb, A. A. Sobaih, B. Abozalam, An Intelligent Maximum Power Extraction Algorithm for Hybrid Wind-Diesel-Storage System", Int. J. Electr. Power Energy Syst., 32 (2010) 170-177.

[13] M. Santoso, Dynamic Models for Wind Turbines and Wind Power Plants, The University of Texas at Austin, January 11, 2008.

[14] R. Babouria, D. Aouzellagb, K. Ghedamsi, Integration of Doubly Fed Induction Generator Entirely Interfaced With Network in a Wind Energy Conversion System, Energy Procedia 36 (2013 ) 169-178.

[15] N. Hamrouni, A. Ghobber, A. Rabhi, A. E. Hajjaji, Modeling and robust control of a wind Generator, International Conference on Electrical Sciences and Technologies in Maghreb (CISTEM), Tunisia, 2014.

[16] F. D. Bianchi, R. J. Mantz, Gain scheduling control of variable speed wind energy conversion systems using quasi-LPV models, Control Engineering Practice, 13 (2005) 247-255.

[17] M. Oudghiri, M. Chadli, A. El Hajjaji, One-Step Procedure for Robust Output $\mathrm{H}_{\infty}$ Fuzzy Control, The 15th IEEE Mediterranean Conference on control and Automation MED’07, Athens, Greece, 2007.

[18] H. O. Wang, K. Tanaka, M. F. Griffin, An approach to fuzzy control of nonlinear systems: stability and design issues, IEEE Transactions on Fuzzy Systems, 4 (1996) 14-23.

[19] K. Tanaka, T. Ikeda, H. O. Wang, Robust stabilization of a class of uncertain nonlinear systems via fuzzy control: quadratic stabilizability, $\mathrm{H} \infty$ control theory, and linear matrix inequalities, IEEE Transactions on Fuzzy Systems, 4 (1996) 113.

[20] E. Kamal, A. Aitouche, R. Ghorbani, M. Bayart, Fuzzy Scheduler Fault-Tolerant Control for Wind Energy Conversion Systems, IEEE Transactions on Control Systems Technology, 22 (2013) 119-131.

[21] S. K. Song, R. Langari, An LMI-based $\mathrm{H}_{\infty}$ fuzzy control system design with TS framework, Information Sciences, 123 (2000) 163-179.

[22] J. Ma, G. Feng, An approach to $\mathrm{H}_{\infty}$ control of fuzzy dynamic systems, Fuzzy Sets and Systems, 137 (2003) 367-386.

[23] S. K. Nguang, P. Shi, $\mathrm{H}_{\infty}$ fuzzy output feedback control design for nonlinear systems: an LMI approach, IEEE Transactions on Fuzzy Systems, 11 (2003) 331-340.

[24] S. Tong, L. Hang-Hiong, Observer-based robust fuzzy control of nonlinear systems with parametric uncertainties", Fuzzy Sets Syst., 131 (2002) 165-184. 